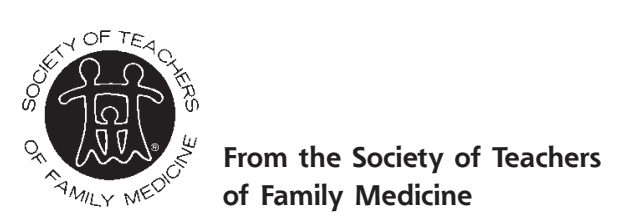

Ann Fam Med 2009;7:187. DOI: 10.1370/afm.973.

\section{INCREASING FAMILY MEDICINE'S LEADERSHIP CAPACITY}

Leadership is defined as "1) the office or position of a leader, 2) [the] capacity to lead, and 3) the act or an instance of leading."1 Throughout the history of family medicine, many individuals have served in the office of a leader, and we can cite many examples of leading. As a discipline, however, few programs have been developed to increase our capacity to lead.

"Leadership and advocacy" is the 10th recommendation of the Future of Family Medicine Task Force. ${ }^{2}$ Arguably, it is the most neglected of the 10 recommendations. While much progress has been made toward many of the other goals of this report, the leadership piece has been missing.

Family medicine currently stands at a unique and important crossroads in its history. We have a new Congress and presidential administration who understand the importance of primary care in the health care system. Business and industry have rallied around the concept of the patient-centered medical home as a method for provided effective, cost-efficient health care. Patients want to develop a personal relationship with their physicians. As family physicians, we need to capitalize on these opportunities by expanding our leadership role. Yet, we have neglected the development of new leaders that would help to accomplish this.

To correct this, family medicine organizations are developing leadership programs that will identify and train new family physician leaders. Specifically, the Society of Teachers of Family Medicine (STFM) has convened a special task force that is creating a leadership development institute.

Members of the STFM leadership development task force include: Terry Steyer, MD, task force chair, Medical University of South Carolina; Jeri Hepworth, PhD, vice-chair, University of Connecticut; Steve Bogdewic, $\mathrm{PhD}$, Indiana University; Marjorie Bowman, MD, MPA, University of Pennsylvania, Dennis Butler, PhD, Medical College of Wisconsin; Amy McGaha, MD, American Academy of Family Physicians; Peter Nalin, MD, Indiana University; Trish Palmer, MD, Pisacano Leadership Foundation; Mark Stephens, MD, MS, Uniformed Services University of the Health Sciences; and Stephen Wilson, MD, MPH, University of Pittsburgh.
With these members representing the broad spectrum of family medicine, this committee is developing a process to identify potential leaders for our discipline and recruit them to participate in a longitudinal curriculum that will teach leadership skills, both for organizational leadership as well as general leadership concepts. These ideas have just begun to take shape, and we plan to launch the first Leadership Development Institute at our 2010 Annual Spring Conference in Vancouver, British Columbia.

As this program and others begin to develop and take shape, you can play a role in developing new leaders for our discipline. Talk with students and residents about the importance of being a leader in their schools, hospitals, and communities. Identify ways that you can advocate for the needs of your patients. Take advantage of leadership opportunities that present themselves to you. And don't be afraid to ask for help if you need it. Working together, we can ensure that family medicine will redefine leadership and will lead the way to a new health care system that can meet our nation's needs.

Terrence E. Steyer, MD,

Medical University of South Carolina

\section{References \\ 1. http://www.merriam-webster.com/dictionary/leadership. Accessed Jan 23, 2009. \\ 2. Future of Family Medicine Project Leadership Committee. The future of family medicine: a collaborative project of the family medicine community. Ann Fam Med. 2004;2(Suppl 1):S3-S32.

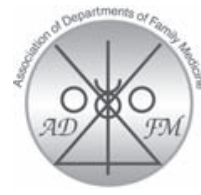 \\ From the Association of Departments of Family Medicine}

Ann Fam Med 2009;7:187-188. DOI: 10.1370/afm.969.

\section{A CALL FOR NEW LEADERS: BUILDING A PIPELINE FOR THE FUTURE OF FAMILY MEDICINE}

The need for family medicine (FM) leaders in departments in academic and medical institutions, health related organizations, and government is rapidly growing, yet the pipeline is running dry. In recent years, numerous chair searches have yielded few applicants and the shortage is getting worse, even as the need for more leaders grows in and beyond our discipline.

We believe all family medicine organizations must identify and prepare future leaders. Towards this end, the Association of Departments of Family Medicine has begun a long-term initiative to develop future 
chairs. Our hope is to prepare talented faculty for chair positions and other major leadership roles, and for other FM organizations to bolster their own pipeline efforts.

\section{Why Be a Chair?}

Jim Jones, former chair at East Carolina University and AAFP Past President, commented, "I had most fun as a residency director, but did the most good as a chair." Chairs build programs, nurture trainees, and make a difference for our regions and states. Being a chair allows highly stimulating engagement in multiple missions and on multiple levels. Chairs gain the immediate gratification of helping a patient or teaching a student, the joy of training the next generation of family physicians and faculty, and the long-term satisfaction of growing departments, medical schools, and health care systems.

\section{What Do Chairs Do?}

Departments of Family Medicine vary from faculty of 8 to more than 150 and annual budgets of $\$ 2,000,000$ to $\$ 70,000,000$. Chair roles vary accordingly, from a focus on administration and patient care, to emphasis on teaching and scholarship, to strategic leadership of large, complex enterprises.

Family medicine chairs lead from the front: $78 \%$ of chairs see patients more than 1 half-day a week, and almost $75 \%$ take calls regularly. More than threequarters teach students, and 92\% regularly teach residents. Chairs' role in scholarship is critical. Many run research grants, regularly publish peer-reviewed papers, and edit textbooks and journals.

Equally important is what chairs do outside their departments. Chairs increasingly play major roles in leading their universities' clinical, research, and educational enterprises. Chairs often lead statewide taskforces and over one-half report extensive involvement with their AAFP state chapters. Nationally, chairs play major roles in family medicine organizations and increasingly outside of family medicine in venues ranging from NIH to the American Cancer Society. Contributing to real change is why many chairs choose to be chairs. Given the scope of the current problems in the American health care and academic system, more chairs and FM leaders are needed than ever before!

Balancing personal life and chair life can be challenging. More than one-half work $>60$ hours a week, and there are often substantial additional urgencies- eg, the Dean or CEO wants something by Monday! Support and camaraderie with other chairs in one's institution and within ADFM are invaluable, as are frequent "rebalancing exercises". Having substantial control over one's schedule helps.

\section{How Can You Prepare to Become a Chair?}

Chairs must be familiar with the spectrum of departmental missions: clinical service, education, scholarship, and advocacy. Individuals aspiring to chair roles should gain leadership experience in more than 1 mission.

Effective oral and written communication skills are essential for a chair: leadership depends on the ability to articulate a vision and to attract partners. Personnel management, though time consuming, is especially important for new chairs who may find a bevy of problems awaiting their arrival. Financial stewardship is also critical: "no money, no mission."

Given these needs, it is not surprising that $73 \%$ of chairs have served as residency directors, 32\% have served as Family Medicine Center directors, and almost one-half have been a principal investigator (PI) on a Title VII grant. Less common are stints as predoctoral director $(22 \%)$ or PI on an NIH grant (14\%). Additional training can be helpful, in the form of advanced degrees or more focused didactic experiences, such as ones offered by Wharton, Harvard, and the American College of Physician Executives. National leadership experience in organizations like STFM, NAPCRG, AAFP, AFMRD, and AAMC is invaluable.

ADFM offers a Senior Leaders Program, Chairs Pipeline Fellowship, and a Mentorship Program for new chairs to help develop future leadership. These provide exposure to leadership across all missions, introduce best practices and innovations in the discipline, and supply feedback and mentoring around skills necessary for chairs.

Family medicine needs skillful leaders who want to make a difference, to build others, build institutions, and to contribute to bettering society. Please contact your chair or ADFM if you would like to learn more.

This commentary was written by members of ADFM's Chair Pipeline Taskforce,

Warren Newton, MD, MPH Jeffrey Borkan, MD, $\mathrm{PbD}$ Hal Williamson, MD, MSPH Michael Magill, MD and the Association of Departments of Family Medicine 